\title{
Television humour and preferred meanings in the Catalan identity debate
}

\section{Luisa Martínez-García}

Autonomous University of Barcelona, Spain

\begin{abstract}
This article analyses a sports-related satirical-parody television series as a generator of preferred meanings that may be associated with an ideological context of a stateless nation such as Catalonia, where the symbolic aspect is fundamental to the imaginary-building process. In this case, the research focuses on identifying whether representations of difference exist in the humorous content of the television series and, if they do, how they are represented and whether they propose imaginary boundaries. Through a quantitative and qualitative analysis in a satirical-parody television series about sports-related news, this study shows that humour generates symbolic boundaries between two spaces. While one of the spaces is in close proximity to the context in which the series is produced and broadcastCatalonia-, the other encompasses the rest of Spain. In the same direction, humorous audiovisual text contains preferred and also dominant meanings, and these are expressed by how characters valuate other characters, situations, contexts, etc. The nature of the valuations proposes meanings that express the idea of a positive "us" and a negative "them". Television humour acts as a cultural agent that proposes preferred meanings to the subject, and such meanings become part of the subject's identity process.
\end{abstract}

Keywords: television series; ideology; Catalan nationalism; fiction; humour and preferred meanings.

\section{Introduction}

This article analyses how a television satirical-parody series proposes dominant or preferred meanings and creates representations of difference in a context within which the national discourse is present in nearly all of the subject's day-to-day spheres. Humour as a generator of meanings that form part of the cultural-identity process of a subject, class, social group, race, 
gender, etc. We know that the media propose images of the world and that such images evince "the power and point of view of the political and economic elites who operate and focus it" (Gamson et al. 1992: 374).

The theoretical and methodological framework of this study is underpinned by the sociology of Bourdieu (2002) on difference as a quality inherent to the subject and the social world as an individual and collective coproduction, and by the British cultural studies' idea of polysemic texts "organized into dominant or preferred meanings" (Hall 1980: 134).

The analysis is divided into two parts: the first one is quantitative and the second one is qualitative. In the quantitative stage, I recorded the humour techniques used in the series and identified the valuations expressed by the series' characters (explicit and implied). In the qualitative stage, I organised and analysed the valuations (explicit and implied) to establish who and what was being valuated in the series. Using this combination of analytical methods, I have tried to illustrate how and in what way the humour in an audiovisual text proposes preferred or dominant representations and also of difference.

My approach is that humour is determined by the logic of its narrative techniques, by the technology through which it is articulated, by the market and by the social and cultural flow. In turn, all of this is understood in the context within which it is produced and broadcast, in this case in a context of Catalan nationalist debate.

\section{Humour and symbolic boundaries}

Humour studies conducted from a sociological focus conclude that culture determines humour's characteristics (Burke et al. 1999). But humour is also determined by the demands of the media market; the messages create stereotyped content not only to facilitate their comprehension but also to ensure that they reach a bigger audience (Crane 1992). In addition, stereotypes in a humorous story serve to construct the idea of otherness (Jontes 2010).

Among other things, humour is a symbolic construction associated with the projection of social boundaries (Kuipers 2006) and with functions such as the creation of social identity and ties of solidarity (Archakis \& Tsakona 2005). Humour is an ambivalent cultural device, but "it is important to understand humour and humorous 'boundary work' first and foremost as mechanisms of social inclusion and alliance" (Kuipers 2006: 243).

Anthropology considers that humorous expressions contain social and, therefore, identity imaginaries (Driessen 1999). For this study, the imaginaries are the set of symbolic elaborations of what we observe (Canclini 2007: 90). So, humour is a social representation tool and an entertaining interaction tool (Rod 2007).

In principle, we know that "any society/culture tends, with varying degrees of closure, to impose its classifications of the social and cultural and political world" (Hall 1980: 134). The globalisation and flow of messages conveyed via the Internet tests the penetration of such messages, and there are studies showing that local cultures react in three ways: they accept them, they interact with them or they reject them (Shifman 2009).

The study is very much in keeping with the works carried out by Davies (1982), who expressed the idea of ethnic humour, the characteristics of which are determined by social, moral and geographical boundaries. Romero et al. (2007) conducted a study that found significant differences between the regions that make up the United States.

Humour is studied not only to observe the boundaries that it proposes, but also as an element that unites individuals; such is the case of the study of Jewish representations in the sitcom Seinfeld (Krieger 2003). 
To understand the elements that the humour of a television product comprises, it is necessary to draw on the superiority category (Berger 1998; Chapman \& Foot 2007; Meyer 2000; Raskin 1985) as a tool that validates one social group over another. Transferring that to my study, it is important to establish whether or not the humour in television series proposes negative and/or positive representations of certain social groups.

Studies on race and humour analyse the comedic representation of characters belonging to certain ethnic groups; or they provide an analysis of how humour serves to cover a review about everyday reality (Paolucci \& Richardson 2006). Such studies often include a social group, subject, race or gender that acts as a point of reference, of comparison, to foster the observation of exclusion-inclusion processes.

Studies conducted by Kuipers have shown a direct relationship between humour and social background, and she found that "American conceptualizations of good humor are more varied, less exclusive, and more moral than any of the humor styles found in Netherlands" (Kuipers 2006: 239).

\section{Identity and humour in media contents}

The symbolic field is undeniably one of the subject's spaces that has changed the most since the invention of cinema, radio, television and the Internet. However, television has become a privileged space in the subject's family sphere; it forms an active part of the subject's day-today life and intervenes in it as a cultural agent. I understand the idea of television and humour as cultural agents in the sense posited by Certeau (1999), as media that perform different functions in the cultural field, such as creators, facilitators, critics, disseminators, etc.

This explains the realignment of the media within the social structure. They are no longer considered only providers of information, not only mediators between the real and the representation, but as a platform from which individuals can claim and report civically and democratically. Being suppliers and being intermediaries, the media, from the sociological point of view, perform the role of social actors. "The power of television is, at the same time, a factor of transnational communication and an agent of national sovereignty. The originality of the television is able to do both: to be an element of the social bond within a national community and to be an element of communication between the different national identities" (Wolton 1995: 290).

Audiovisual texts are popular because they are able "to give pleasure to as wide a range of audiences as possible" (Fiske 1986: 403), though decoding and use will be fully and/or partially dependent on their sharing an ideological frame. Here, ideology is understood, in its broadest sense, as a series of values and ideas that a social group constructs and shares (Williams 2003). Thus, "a wide variety of media messages can act as teachers of values, ideologies, and beliefs and [...] can provide images for interpreting the world whether or not the designers are conscious of this intent" (Gamson et al. 1992: 374). Another idea guiding this research is that audiovisual texts respond to a structured polysemy (Morley 1996) and require a preferential reading, implying that the content of such texts has to be understood within the codes and ideologies of the series in question. Fiske (1986: 403) states that "The preferred reading of a popular text must necessarily, then, attempt a hegemonic function in favor of the culturally dominant".

The presence of identity in the media has produced a series of transformations. For Sampedro (2003), these can be summed up by the idea that, in the media, there is present not only an idea about "Us", but also, about "Them". The omnipresence of the media in our 
everyday lives increases the incidence of identity-related elements and shapes them as a decontextualised input from which the viewer (subject) has to choose. Identity-related elements not only multiply, but also diversify "creating multiple identities for those consuming them. Identities that cover areas as diverse as fashion, music, religion, or sport" (Sampedro 2003:13).

The flow of representations that television offers us forms part of our symbolic raw material, from which we construct ideas of the world, of the "other" and of "us". Television "needs to commodify real and imagined nations while being open to global flows of ideas and money" (Waisbord 2004: 367). The torrent of symbolic imaginary presented in the late 20th century, especially by information and communication technologies, has given rise to radical changes in the cultural syntheses developed by people all over the world (Lull 1997: 93). And television humour is not exempt from this ambivalence, as mentioned earlier.

It is worth recalling that the whole process of identity construction implies a practice of exclusion and inclusion, of recognition and of difference. "Looking at the rest of the world through television, it is inevitable that differences can be celebrated and erased, recognized and removed, insisted upon and ignored" (Hartley 2000: 12). Difference as a consequence of the "other" or, as Rutherford (1990: 10) put it, "difference as a motif for that uprooting of certainty". Thus, it is the cultural apparatus, in which the media are included, that, among other things, produces a nation (Morley 1996).

Any communication explicitly has a strong load of identity representation. In the words of Wolton (1995), there is no communication without identity (Wolton 1995: 277). If we take this assertion to a structural level, then it could be said that there is no society that does not impose its own worldview, which the media are responsible for disseminating. This is what Hall (1980) conceives of as the "dominant or cultural order", on which he notes that "The different areas of social life appear to be mapped out into discursive domains, hierarchically organized into dominant or preferred meanings" (Hall 1980: 134).

The process of appropriation and consumption of media content is important but not decisive for shaping a cultural identity. The content is part of the social. "The millions of images that float in the public imagination help determine the nature of national loyalty, attitudes toward places, family, and state government" (Price 1995: 1).

What is clear is that humour and identity express themselves in the subject's cultural field, and that they provide the subject with preferred meanings, the reading of which has to be understood in the message-production and distribution setting, which, in our case, is a stateless nation.

\section{Catalan and Spanish media and ideological context}

The social reality is more complex and leads me to think of specific contexts like, for example, those in which the nation-state structure is missing. I am referring to stateless nations that have a language, a culture and their own communication space like Catalonia (one of Spain's seventeen autonomous communities), the nation in which the TV series -the object of study of this research-was produced.

The apogee of Catalan culture, witnessed at the beginning of the 20th century, was undermined for thirty-six years under the Franco dictatorship. The fractures that Catalonia had suffered in its development as a nation, primarily in the linguistic area, have now largely been healed due to the spur provided by different aspects of the resulting normalisation process. 
One of the institutions created shortly after the approval of the Statute of Catalonia, was the CCRTV (Catalan Radio and Television Corporation) in 1983. The use of the Catalan language, within the Catalan television system, has been an indispensable tool in the reestablishment of the language and of Catalan cultural identity, as argued by Moragas (1988) in his book Communication Spaces.

The presence of Catalan is virtually negligible within the networks which broadcast throughout Spain and this allows us to understand and justify the legal framework behind the use of the Catalan language in the media whose catchment area is confined to Catalonia. These arguments also lead to the idea of reinforcement and consolidation of a Catalan communicational space (Moragas 1988) to safeguard and invigorate culture and language in Catalonia.

Televisió de Catalunya (TVC), through its first channel, TV3, began broadcasting regularly in 1984 in a context of political and social transition. Catalonian public TV, TV3, broadcasts all its programming in Catalan. As argued by Moragas (1988) in the text Communication Spaces (1988), the use of Catalan language in the Catalan television system is an indispensable tool for the recovery of the language and the cultural identity. According to Gifreu (2001: 148), TVC is a Catalan televisual imaginary that serves as an alternative to the dominant Spanish televisual imaginary of reference, the latter being offered first by TVE (the Spanish public-service channel) and then by state-wide private channels. This is so not only because of the institutional use of the Catalan language, but also because of a preferential viewpoint and an intentionality that places the interest of the Catalan space ahead of the Spanish one.

The political context within which the object of study is produced is characterised by the rise of pro-independence movements. In 2005, the Catalan Parliament approved a new Statute of Autonomy, in which, among other things, Catalonia is recognised as a nation that uses Catalan as a preferential language. Indeed, the latter two characteristics were precisely those that generated most political debate within the Spanish sphere and led Spain's conservative party to take legal recourse against the Statute. The Statute was finally modified by Spain's Constitutional Court in 2010. The modifications relevant to this study stipulated that there is no nation other than the Spanish nation, and that the official languages in Catalonia are Spanish and Catalan. This has become a hotbed of dissent, and, since 2006, has led to pro-independence demonstrations by the public and some politicians. The discourse has worked its way into almost every aspect of daily life in Catalonia, and public-service media like TVC are no exception.

Finally, TVC's political and ideological dimension is undeniable. According to Fecé (2003: 293), TVC functions like an impressive propaganda machine at the service of the governing powers.

\section{Crackòvia satirical-parody television series}

Cultural Studies is the framework within which numerous studies on popular culture products have been conducted. Morley (1996: 25) states that “... the analysis of media products that explicitly define themselves as non-political is in fact of central concern to any analysis of political culture". The series that is the object of this study does not belong to the elite cultural products group, but it is nonetheless meaningful. On occasions, televisual products like football have actually been labelled as topics that are "not serious". However, according to Villena (2002: 134), football as a sport is a ritual scenario that symbolically enables structural 
differences between individuals to be averted and, furthermore, fosters their immersion within a space of communitas, of communion between those who are often structurally separated by role and status differences.

Crackovia is the title of the television series, being broadcast on TV3, on which the analysis focuses; it is a sports-related satirical-parody television series in which sport and humour converge. Sport and humour are social devices that construct cohesive and/or divisive identity processes.

Since Crackóvia was first broadcast in the primetime slot on Catalonia's channel TV3 (which broadcasts only in Catalan) on 15 September 2008 (coinciding with the start of the 2008 UEFA Champions League), it has been in the top 20 most-viewed programmes in Catalonia (in 2008 and 2009) ${ }^{1}$. It had an audience share of 27.2 per cent in the first year, rising to 29 per cent in the second year. Crackovia's success on Catalan public-service television is so great that the format was sold to Telemadrid, the regional public broadcaster of Madrid. A Spanish version, featuring Real Madrid and Atlético de Madrid as its parodies, was broadcast on 30 August $2010^{2}$.

Crackovia's success is not only reflected in television consumption, but also in its remarkable presence on the Internet; the series was the most downloaded video podcast (88,495 downloads) from the TV3 website in 2009. Moreover, the study conducted by Antonio Lavado (2010) on YouTube consumption in Spain shows that football-related videos are the most viewed (those connected with FC Barcelona and excerpts of the TV3 series Crackòvia). It is not the aim of this research to make an analysis of humorous representation of football. But it recognises that football is a space for identity interactions and is more present in the area of academic study and, as Villena (2002) says, sport transformations pass through a sharp marketing and trans-nationalisation process.

Finally, studies of television series as identity-dialogue spaces in the context of a stateless nation like Catalonia, where nationalist debates within the framework of the Spanish nation-state are constantly at the top of the agenda, are urgently needed in order to understand the subjects' day-to-day sphere.

\section{Research questions}

The objective of the study is to establish whether a television parody series generates preferred meanings, if it does, if those symbolic boundaries are linked to and/or can be explained by the ideological context within which the product is produced and broadcast. On the one hand, this work tries to understand how humour is expressed and what its narrative techniques are in a context within which there is an identity split. On the other hand, it aims to understand the meanings of difference generated by an audiovisual text and the spheres to which they are related.

The research questions are:

RQ1: Does Crackòvia's humour generate preferred and/or dominant meanings?

\subsection{Specific questions}

RSQ1: Does Crackòvia's humour propose meanings related to the prevailing national ideology in Catalonia? 
RSQ2: Does the sketches' language determine the characteristics of the meanings?

RSQ3: Does the series' humour propose meanings that express differences between groups?

RSQ4: Does the series' humour propose meanings that express affiliations or disaffections?

RSQ5: Do the series' characters allude to groups that play lead roles in some type of nationalist imaginary?

\section{Method}

In order to respond to the questions posed, quantitative and qualitative methodologies were designed. Through content analysis, the quantitative approach aims to provide a detailed picture of the series, describing it to identify the type of humour that characterises it. Through Critical Discourse Analysis (CDA), the qualitative approach aims to perform an in-depth analysis of the topics, characters and valuations present in the comedy sketches to establish the nature of the valuations and whether their meanings indicate differences between "some" and "others" on the one hand, and the contextual spheres to which they refer on the other.

\subsection{Quantitative instrument and procedure}

I performed content analysis using SPSS with independent categories, with ordinal rating, structured into three sections:

- The first section was descriptive (broadcast date, start time and end time, language used in the sketch, protagonists and secondary characters). A fundamental category is that of the language as a basic representation system in the construction of meaning (Hall 1977). Also noted was the existence of verbal references to other characters and the explicit and implied valuations made by the sketches' characters, that is to say, the verbal judgments made of/about subjects, institutions, organisations, etc.

- The aim of the second section was to differentiate between the spheres within which the action was taking place and the spaces verbally mentioned.

- Finally, in the third content analysis section, I drew on the humour techniques validated by Buijzen \& Valkenburg (2004) -who, in turn, had drawn on Berger $(1976,1998)$ - in their study of the development of a typology of humour in audiovisual media (cf. Table $1)$.

Table 1. Humour techniques

\begin{tabular}{|l|l|}
\hline Humour Technique & Concept \\
\hline Slapstick & $\begin{array}{l}\text { Making humour at the expense of others, often including violence. } \\
\text { It is a type of physical comedy such as throwing a pie into } \\
\text { someone's face. }\end{array}$ \\
Checuliar face & Characters pull funny faces. \\
Peculiar voice & A funny voice. \\
Coincidence & An unexpected occurrence. \\
Clumsiness & A lack of agility or grace.
\end{tabular}




Stereotype
Ridicule
Malicious pleasure
Repartee
Conceptual surprise
Visual surprise
Transformation
Exaggeration
Irony

Sarcasm

Pun

Scale

Clownish behaviour

Peculiar music

Misunderstanding

Ignorance

Disappointment

Peculiar sound

Parody

Bombast

Outwitting

Rigidity

Absurdity

Infantilism

Imitation

Impersonation

Eccentricity

Sexual allusion

Repetition

Grotesque appearance
Embarrassment

Talking in a stereotyped or generalised way about a group, collective and/or member of a nation, gender, etc.

Making someone look ridiculous.

Making fun of someone else's misfortune. Making humour about the victim.

Verbal jokes, usually through a witty dialogue.

The narration tries to lose the audience with an unexpected event.

There is a change in narrative genre.

An unexpected visual event or a physical change.

Someone who takes on another form or undergoes a

metamorphosis.

Someone who exaggerates or reacts in an exaggerated manner, e.g. when he/she exaggerates the virtues of a product or a person.

When someone is saying something and it means something else, generally the opposite of what is being said.

A cutting remark made in a hostile tone.

An uncomfortable situation in which someone feels disgruntled, annoyed or embarrassed.

A play on words suggesting two meanings.

Objects and/or people that is big or small, or tall or short.

Exaggerated movements of the arms and legs. Exaggerated gestures.

Unusual, funny music.

Misinterpreting a situation.

Someone who behaves in a silly, naïve or childish way.

A situation leading to a minimum of disagreement.

A funny sound or an unexpected sound. (Musical effects).

An imitation of a literary style or genre, or that of another medium.

Talking bombastically or rhetorically.

Systematically getting one up on someone.

Someone who thinks along narrow lines, who is inflexible and conservative.

A situation that goes against all logic and its rules.

Playing with the sound of words.

Mimicking someone's appearance.

Taking on someone else's identity, intentionally or otherwise.

Someone who deviates from the norm and has an odd, extravagant

character

A reference to sex.

Repeating the same action, situation, gesture, etc.

Someone who has a bizarre, monstrous appearance.

Source: Based on Berger $(1976,1998)$, Buijzen \& Valkenburg (2004).

Finally, content analysis has been widely used in studies of humorous messages (Scharrer et al. 2006; Paolucci \& Richardson 2006; Cooper 2007; Furnham \& Farragher 2000; McIntosh et al. 2006).

\subsection{Qualitative instrument and procedure}

Critical Discourse Analysis (CDA) was used to perform the analysis, because it is the method that situates the text within the context, thus explaining and positioning the meaning within a 
frame. According to Fairclough (1995), discourse functions in three ways. The first refers to discourse and the use of language as a social practice. The second defines discourse as a type of language used in a field. The third considers discourse as a way of speaking that produces meanings and experiences from a hegemonic perspective.

These are the three ways that mark the development of the CDA itself, which has been organised in accordance with the guidelines proposed by van Dijk (2003):

- Transcribing the Crackòvia sketches and loading them into TAMS Analyzer.

- Identifying about whom people are speaking and who the protagonists of the sketches are.

- Performing an analysis of the conversation by analysing the topics.

- Identifying the visual, sound and/or audiovisual referents and the field to which they allude. In this case, we decided to categorise the fields into Spanish, Catalan and global. It should be noted that they are non-exclusive categories and that there may be more than one in a sketch.

- Determining the local semantics in the sketches' conversations in order to identify what Dijk (2003) called positive self-presentation and negative other-presentation. Semantics that implicitly valuate are also added, and here we have resorted to those sketches that above all use irony as a narrative technique.

- Recording the use and appearance time of canned laughter in the sketches (noted down using "CL" as an abbreviation), and both were related to each of the previously mentioned analysis categories. Canned laughter operates as an influencing agent that attempts "to capitalize on the social nature of laughter to produce audience laughter" (Platow et al. 2005: 542).

CDA is used in order to try and explore the idea that, like any other message, when a humorous message "...is emitted it is not only what is said that has a significance but also the way it is said, and what is not said but could be said" (Camargo 1980: 124). Indeed, in humorous messages, it is possible to express representations of difference and meanings related to the ideology of the medium via which they are emitted and to the hegemonic ideas of the place in which they were produced.

The methodologies used in this study are complementary and their aim is to explore an audiovisual text and align its meanings to a social context. A chart was produced to make it easier to understand the methodological design. This chart visually represents a summary of the objectives of the quantitative and qualitative methods (cf. Figure 1). 
Figure 1. Representation of the methodological design

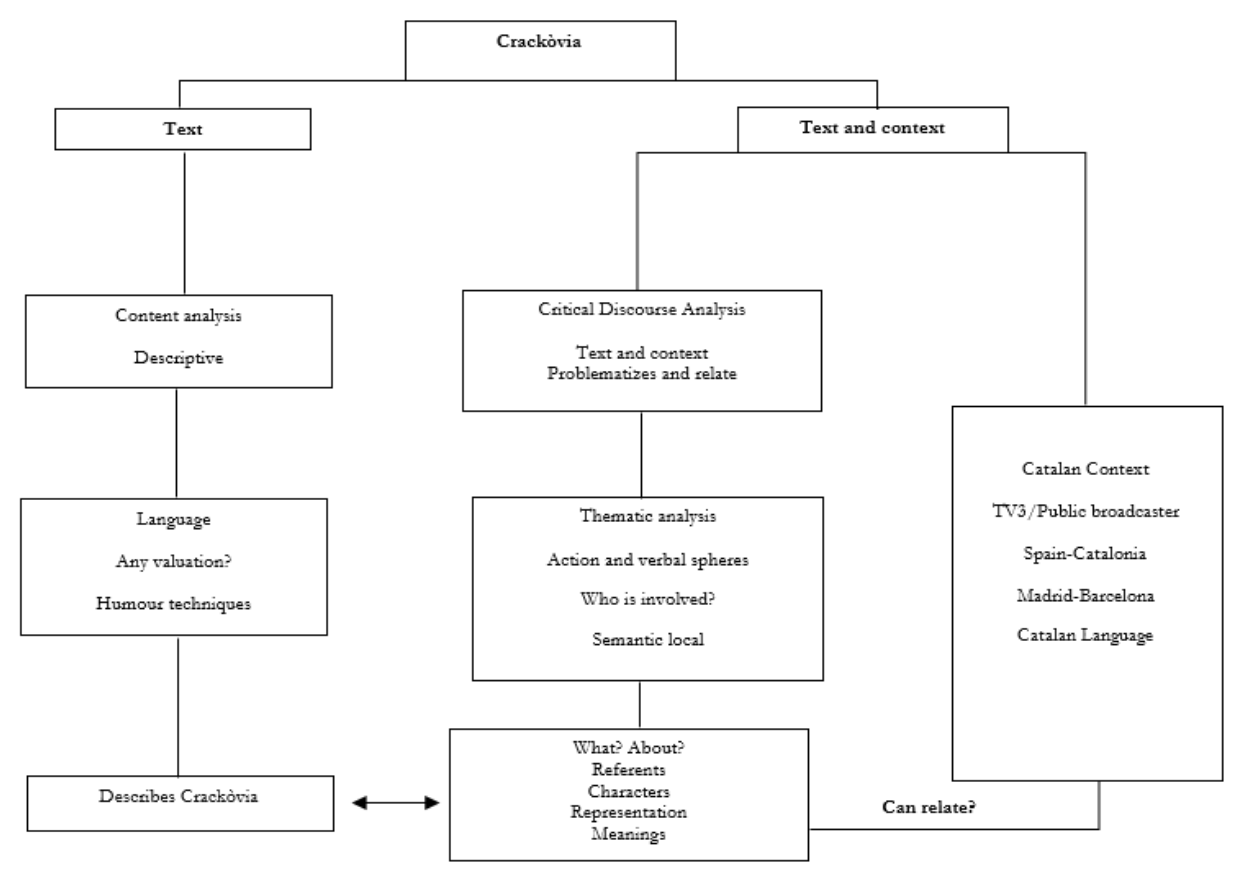

Source: The author

\subsection{Sample}

The sample is intentional, it is the same one for both the quantitative and qualitative analyses, and comprises 93 sketches of the third season series of Crackovia, broadcast between 11 April and 9 May 2011. It is intentional, because these dates coincide with a series of sporting events that generated the news agenda; for the first time in the history of Spanish football, FC Barcelona and Real Madrid met on four occasions (to compete in La Liga, the Copa del Rey and the UEFA Champions League).

Considering that the series is a satirical parody of Spanish sports news (mainly, football), studying the series between these dates is justified, because the media agenda was set by these events, and was able to generate the exploitation of representations of difference.

\subsubsection{Procedure and reliability}

After two weeks of training, two coders applied the quantitative tools and performed the percent agreement and reliability. The percent agreement and reliability tests were performed on a representative percentage of the sample ( 20 per cent), that is, on an episode of the series that did not form part of the analysis.

The test of inter-coder reliability of the 36 categories was performed before the quantitative analysis. The average percent agreement is 93 per cent and the average discrepancy between the two coders is 7 per cent (cf. Table 2). Cohen's Kappa reliability coefficient scores show that 11 per cent of the categories (stereotype, parody, bombast and repetition) have a "moderated" reliability percentage; according to the Landis \& Koch (1977) interpretation guidelines, they are way above the zero degree of agreement. However, in 28 
per cent of the categories (peculiar voice, ridicule, malicious pleasure, repartee, transformation, exaggeration, clownish behaviour, rigidity and absurdity), they present a substantial degree of agreement.

Table 2. Inter-coder reliability scores ( $\mathrm{N}=17$ sketches)

\begin{tabular}{|c|c|c|}
\hline Category & $\begin{array}{l}\text { Percent } \\
\text { Agreement }\end{array}$ & Cohen's Kappa \\
\hline Slapstick & $100 \%$ & 1 \\
\hline Peculiar face & $100 \%$ & Undefined* \\
\hline Peculiar voice & $88 \%$ & 0.77 \\
\hline Coincidence & $94 \%$ & 0.88 \\
\hline Clumsiness & $100 \%$ & 1 \\
\hline Stereotype & $76 \%$ & 0.47 \\
\hline Ridicule & $82 \%$ & 0.64 \\
\hline Malicious pleasure & $88 \%$ & 0.72 \\
\hline Repartee & $88 \%$ & 0.77 \\
\hline Conceptual surprise & $94 \%$ & 0.85 \\
\hline Visual surprise & $94 \%$ & 0.88 \\
\hline Transformation & $94 \%$ & 0.64 \\
\hline Exaggeration & $94 \%$ & 0.64 \\
\hline Irony & $94 \%$ & 0.88 \\
\hline Sarcasm & $94 \%$ & 0.88 \\
\hline Embarrassment & $100 \%$ & 1 \\
\hline Puns & $100 \%$ & 1 \\
\hline Scale & $100 \%$ & Undefined* \\
\hline Clownish behaviour & $94 \%$ & 0.64 \\
\hline Outwitting & $100 \%$ & 1 \\
\hline Peculiar music & $94 \%$ & 0.85 \\
\hline Misunderstanding & $100 \%$ & Undefined* \\
\hline Ignorance & $100 \%$ & 1 \\
\hline Disappointment & $94 \%$ & 0.88 \\
\hline Peculiar sound & $94 \%$ & 0.87 \\
\hline Parody & $76 \%$ & 0.48 \\
\hline Bombast & $71 \%$ & 0.43 \\
\hline Rigidity & $88 \%$ & 0.76 \\
\hline Absurdity & $88 \%$ & 0.76 \\
\hline Infantilism & $100 \%$ & 1 \\
\hline
\end{tabular}

Source: The author

*Undefined means that Cohen's Kappa is unable to evaluate the results because there is no sample variance for these categories. In these cases, the percent agreement is the best approximation to the degree of reliability.

Just under half of the categories (47 per cent) have an almost perfect $\kappa$ between 0.81 and 1. In other words, the inter-coder discrepancies, as the percent agreement shows, are not significant, though they were corrected for the analysis. 


\section{Results}

\subsection{Quantitative findings}

Crackòvia is a product of Catalonia's autonomous community television channel TV3, which broadcasts only in Catalan. However, the joint and simultaneous use of Catalan and Spanish was found in just over half of the series' sketches (53 per cent). In second place was the use of Catalan only ( 28 per cent) and in third place was the use of Spanish (16 per cent). These figures do not agree with the Statistical Yearbook of Catalonia (2008) with respect to the use of language by the population aged 15 or over. The figures in that yearbook show that the first language is Spanish (45.9 per cent), the second is Catalan (35.6 per cent) and the joint and simultaneous use of both is third (11.9 per cent). In this respect and according to statistics, the series proposes a language context that is different from the one in which it is being broadcast (RQ1, RSQ1 and RSQ3).

I developed a dichotomous category between explicit and implied valuations; at this stage of the analysis, the existence or otherwise of valuations of certain topics, subjects and situations was identified. The results of the analysis suggest that the series' characters make, through their dialogues, more explicit valuations (73 per cent) than implied valuations (36 per cent).

To enrich the analysis, taking into account the role of language in the social context of research, I have been prompted to make a chi-square test to establish any potential dependencies between the languages in which the sketches are expressed and the use of valuations. The results show no dependence between Catalan language and explicit valuations.

However, a chi-square test detects a significant dependence in the enunciation of explicit rating in sketches completely in Spanish, $X^{2}(3.84, \mathrm{~N}=93)=5.53$ p. $<0.05$ and in the bilingual ones, $X 2(3.84, \mathrm{~N}=93)=18.73$, p. $<0.05$. In contrast, analysing implicit valuations in sketches in Catalan, chi-square detects a significant dependence, $X 2(3.84, \mathrm{~N}=93)=9.46$, $\mathrm{p}$. $<0.05$. In other words, a chi-square test detects a significant independence between implicit valuations and sketches in Spanish and bilingual ones (RSQ2). And implicit valuations depend only and exclusively on them being expressed in Catalan.

The valuations are not only determined by language, but also by the humour techniques used. In this respect, all the explicit and implied valuations are accompanied by peculiar faces, exaggeration and clownish behaviour; this could be interpreted as the series' particular style of humour.

At least half of the total explicit valuations are accompanied by coincidence (43 occurrences), peculiar music (39) and clownish behaviour (68). When comparing the variety of humour techniques used to express valuations, we can find they are more prolific in implied valuations, despite the fact that they have a lesser presence in the series. In other words, half of the explicit valuations ${ }^{3}$ is accompanied by six humour techniques, while implied valuations are accompanied by 11 . This may be due to the fact that the implied valuations made by the series' characters need to accompany their dialogues with more humour techniques to allow viewers to read between the lines of the constructed message. In this case, humour -and the techniques it employs- serves to express the content of the message more accurately.

Humour techniques operate in three ways: first, on the characters' oral and body language; second, on the characters' context and characteristics; and third, on the devices particular to televisual language that is used to facilitate and strengthen the narration. Berger 
(1998) organises them into techniques that operate on language, logic, identity and action. I have clarified this only to explain that, in the implied valuations, there are techniques that operate on the characters' language (irony, coincidence, sarcasm, ridicule, slapstick and bombast) and on televisual language (peculiar music and visual surprise).

Continuing with the idea of the three ways in which humour operates, I draw on the techniques of televisual language that the series uses as humour techniques (visual surprise, peculiar music, peculiar sound and transformation). The aim of doing so is to explain that three of them (visual surprise, peculiar sound and peculiar music) are important in at least half of the valuations expressed in the sketches for the elaboration of humorous dialogues. The use of such techniques is perhaps the result of adapting humour to the television genre. In both explicit and implied valuations, I would like to emphasise the high percentage of peculiar music (57.3 per cent and 74 per cent, respectively) and peculiar sound (35.2 per cent and 47 per cent, respectively). Both techniques are closer to radiophonic than televisual language, and their function is to stir and arouse the audience's emotions and direct the meaning of the message in this humorous case.

The quantitative results provide the descriptive view of humour as a genre, whereas the qualitative analysis problematises the text, in the sense that texts not only tell or show something, but also tell or show the way in which that something is proposed and captured (Casetti \& Di Chio 1999: 251).

In the quantitative results, according to my design of the content analysis at least, it is almost impossible to establish the nature of the valuations. So it was necessary to complete the study with a textual analysis, to which I added the valuations and canned laughter category, because humour not only consists of narrative techniques, but also of devices that respond to the medium supporting the text.

\subsection{Qualitative findings}

The local semantic analysis was performed on larger language units, i.e. the conversation, in order to identify valuations of positive "us" and negative "them" representations, and to record the space, i.e. the context, to which they alluded, whether explicitly or implicitly.

In the conversations, the results of the textual analysis reveal that the explicit valuations refer almost equally to Spanish contexts (146 occurrences) and Catalan contexts (145 occurrences), and very few to global topics (17 occurrences). In fact, the explicit valuations have a greater presence in two spheres (Catalan and Spanish) and, to a lesser extent, the narrative is related to global representations. Given below are some examples of the conversations alluding to both Catalan and Spanish spheres. They are identified by the sketch number, and the appearance time of canned laughter (CL) is noted in brackets. No examples referring to global spheres are given, because they are not significant to the account of the results.

\section{Catalan context}

\section{Sketch 2}

Pedrerol: Good evening and welcome to "Punto Pelota" (Spanish sportscast). The talking-shop where no matter if Barza (Football Club Barcelona - FCB) wins or loses, we always make their supporters go to bed full of anger (the pundits celebratel CL - 6:11). 


\section{Sketch 6}

Parishioner 1: I think that Messi (FCB player) is a bluff (CL - 16:37).

Parishioner 2 and 3: You say!

Parishioner 1: Scoring goals is not everything and, where is the charisma! , I repeat it: Messi is a bluff (CL - 16:44).

\section{Spanish context}

Sketch 57

Guardiola ( $F C B$ coach): They are right (while he throws away the cross and it falls on Pinto's (FCB player) foot (CL - 10:59). It's okay, I'm tired of being the good guy. Mourinho (Real Madrid - RM coach), one thing I must tell you; I dislike you so much.

FCB players: Good! (CL - 11:08)

Guardiola: And Pepe (RM player) is filthy.

FCB players: Good! (CL - 11:13)

Guardiola: And I hate Marcelo (RM player).

FCB players: Good!

Guardiola: Enough provocations.

Pinto: Right! (CL - 11:15)

Guardiola: Guess what? We went to the Bernabeu stadium (RM stadium) and we raised a hell (CL - 11:21).

Homogeneity is not a characteristic of the implied references. Quite the opposite, in fact, as the number of references to Spanish spheres (35) is much higher than that of references to Catalan spheres (15) and global spheres (6). This peculiarity of the humorous narrative is worth noting, because, while the meanings that are openly expressed qualify both the Catalan and Spanish contexts equally, this rule is broken in the implied meanings as more implied allusions are made to Spanish references than to Catalan references (RSQ3).

Given below are several examples of implied valuations, organised by context:

\section{Catalan context}

\section{Sketch 5}

Iker (TV presenter): Here, it is the first mystery, I am Spanish and I speak Catalan! You are Catalonian and you are named Espanyol. Creepy, right? (CL - 13:57)

\section{Sketch 14}

Florentino Pérez (RM president) to Sandro Rosell (FCB president).

Florentino Pérez: Come and give me one of those pills that you give to your players so I can fall the way they do (CL - 5:44)

\section{Sketch 15}

Guti (RM player): Menys xivarri -in Catalan language- (CL - 7:33) Fuck man, I come to Madrid so I don't have to listen to Turkish and it happens that here Arab is also spoken.

Puyal (radio announcer): I'm Catalan ... (CL - 7:41)

Guti: You see? Cat ... talan (CL - 7:42) Muslims (CL - 7:44). 


\section{Spanish context}

Sketch 34

Cristiano (RM player): I shoot, I shoot.

Di Maria (RM player): Finally, you'll be able to score a goal to Barza, Cristi!

Cristiano: You're right; it's a unique moment and I cannot make it badly (CL 19:04). I have to be just perfect for the occasion.

\section{Sketch 55}

Pizza deliverer: Sergio Ramos (RM player)? He has been a player before being president of Real Madrid (CL - 2:36).

Mourinho (RM coach): Yeah, yeah (CL -2:40), that player's mind was a medical case $(C L-2: 45)$ that science (CL - 2:49) was unable to understand (CL - 2:53).

\section{Sketch 63}

Mourinho (RM coach): We need to throw him a bone to calm him down.

Sergio Ramos (RM player): A chicken bone?

Mourinho: No! It would be preferable a shin bone (CL -20:31) Manolito (RM player), you'll have to give us your shin bone; anyway, you don't use it (CL - 20:37).

\section{Sketch 75}

Cristiano (RM player): And why don't we train in the field? Instead of training for the press conference (CL -9:03).

Di María (RM player): Yes, Cristiano is right (CL - 9:06).

Mourinho (RM coach): Training in the field? What nonsense! (CL - 9:10)

Di María: You have such weird ideas! (CL - 9:12)

That is, the meanings found in the audiovisual text are related in a preferential manner with a Spanish and Catalan context. So, it is clear that the humour of the series builds an identity space and this focuses on the conversation between the context of the Spanish state and the Catalan context, both of which are protagonists in the Catalan nationalist debate (RSQ3).

\subsubsection{Conversation topics by valuations}

The reading of the qualitative results was made by combining the three analysis categories: topic description, spaces of reference in which the action takes place and/or those that are verbally expressed.

Half of the content of the explicit valuations refers to Spanish and Catalan football characters (cf. Table 3). It is interesting to find that the evidence supports that almost half of the series' valuations and expressions of difference fall on football characters, whose protagonists are the managers of Real Madrid (70 per cent) and FC Barcelona (42 per cent). In this case, it has identified the use of preferred meanings (RQ1). 
Table 3. Topics of the explicit valuations

\begin{tabular}{lrrrr} 
& \multicolumn{4}{c}{ Explicit valuations } \\
\cline { 2 - 5 } & Spanish & $\begin{array}{r}\text { \% category } \\
\text { related }\end{array}$ & Catalan & $\begin{array}{r}\text { \% category } \\
\text { related }\end{array}$ \\
\hline Football character & 77 & $53 \%$ & 70 & $48 \%$ \\
Football item & 25 & $17 \%$ & 33 & $23 \%$ \\
Real Madrid & 23 & $16 \%$ & 0 & $0 \%$ \\
FC Barcelona & 0 & $0 \%$ & 23 & $16 \%$ \\
Media items & 12 & $8 \%$ & 5 & $3.4 \%$ \\
Media character & 3 & $2 \%$ & 8 & $5.5 \%$ \\
Real Madrid fans & 5 & $3 \%$ & 0 & $0 \%$ \\
FC Barcelona fans & 0 & $0 \%$ & 4 & $3 \%$ \\
Language & 1 & $0.6 \%$ & 1 & $0.6 \%$ \\
Political items & 0 & $0 \%$ & 1 & $0.6 \%$ \\
Source: The author & & & &
\end{tabular}

At this point, it is important to say that Catalan citizens and politicians -from mid 2012- have stimulated the independentism's debate which has been reinforced by two facts: one large demonstration that took place on 11 September through the main streets of Barcelona and another one in Barcelona FC's stadium where a match between Real Madrid and Barcelona FC took place on 7 October. In fact, Barcelona FC's slogan is "Barcelona FC more than a club". It is undeniable that football in Catalonia is important for the symbolism that subjects give to Football Club Barcelona (FCB). For this reason, the study of cultural and social synergies generated around this club is important to understand part of the Catalan national narrative. Indirectly, the analysis of the football theme is a way to understand the idea that FCB is more than a club. Definitely in Catalonia, Barcelona FC is an important Catalan referent but also it is a space where tension between Spanish and Catalan things exists (RSQ1).

In a study on the image of Catalonia conveyed by Spanish television channels (Collantes et al.), sport, art, culture and politics were identified as agenda-setting topics. Moreover, some topics were related, such as FCB-RM and the cities of Barcelona and Madrid.

Nearly all the explicit valuations, except for the political and language topics, allude to the context of football (RQ1). It is worth recalling that the study sample is intentional, and that the dates of the episodes analysed coincide with important football events on both Spanish and worldwide scales. This also bears witness to the fact that football dominates the media's sporting agenda and even of some products of fiction like Crackòvia.

They focus the implied valuations referring to Catalan contexts (15) on football players (5), sports media (1), other teams -neither FCB nor RM- (2), the FCB coach (1) and a former football player (1). The remaining implicit valuations are expressed almost equally and refer to FCB (2), the Catalan language (2), the political system (2), the media (3) and another Catalan football team (1). What stands out in this category is that most of the implied valuations allude to Spanish contexts (35) and, in this case, 62 per cent refer to the RM coach Mourinho (RQ1, RSQ3). 


\subsubsection{Representation of local semantics (positive "us" and negative "them")}

In the audiovisual text, the dominant valuation is more than explicit in the expression of negative representations. In this case, they concentrate on a single individual, who is a point of reference in the Spanish sphere (RSQ3). These results show the synergy of differences needed in the construction of "us" (the Catalan sphere) and "them" (the Spanish sphere). So the boundaries between "some" and "others" are expressed in the eternal struggle between the representation of good and bad. The supremacy of the "good" over the "bad" is a universal topic of fiction that, through humour, proposes meanings of phobias and philias. "An important reason why humour is appreciated by some people, but not by others, is that knowledge is required to understand humour" (Kuipers 2009: 225).

Real Madrid and FC Barcelona "hate each other with intensity than can truly shock the outsider" (Ball 2011: 17). Most of the valuations are expressed by qualifying adjectives that highlight positive or negative aspects of both football teams. But, in the case of the Real Madrid manager, 76 per cent of the valuations are negative (dominant meaning, RQ1, RSQ3, RSQ4, RSQ5); they describe him as being complaining, vindictive, bad-tempered, overdramatic and a victim. The aforementioned adjectives are verbally expressed in the sketches.

Given below are some examples of conversations that qualify Mourinho as the "negative other" (RQ1, RSQ3, RSQ4 and RSQ5). They are identified by the sketch number, and the appearance time of canned laughter (CL) is noted in brackets.

Mourinho, qualified as the "negative other"

Sketch 77

Guardiola (FCB coach): If (CL - 12:33) It's been two weeks that I've listened to this simple man explaining stories, he keeps on thinking he is the fucking master (CL 12:39); he is always contaminating (CL - 12:42).

Mourinho (RM coach): Those were true stories but Barza did not like them. They even denounce them to the UEFA (CL - 12:50).

\section{Sketch 81}

Guardiola (FCB coach): We must be cautious (CL - 22:56).

Grau (TV journalist): With answers like those, he thinks he is the most modest man on earth (CL - 23:00).

Guardiola: No, I still must learn a lot (CL - 23:03).

Grau: You see how modest he is? He is worried about the Catalan press being so partial, supporting this childish and liar that Mourinho (RM coach) is (CL - 23:12).

\section{Sketch 89}

Mourinho (RM coach): It's true, but if UEFA (Union of European Football Associations) keeps on punishing players, we will need to sign many more players. Grau (TV journalist): But you have such a big staff, soon Bernabéu (RM stadium) will have more people on the bench than in the stands (CL - 13:08).

Mourinho: We have no defence players, we have no centrals, no attackers, and we have no shame (CL - 13:14). 
In contrast, the "positive us" is expressed mostly by explicit adjectives in conversations referring to the FCB manager, 55 per cent of which are positive (dominant meaning, RQ1, RSQ3, RSQ4 and RSQ5); they describe him as humble, wonderful, friendly, good, modest, supportive, a winner and even a hero.

\author{
Pep Guardiola, qualified as the "positive us" \\ Sketch 2 \\ Pundit 3: Little Roncero (a pundit), I'm kidding, they have not played yet. \\ Roncero: But they are worse than Guardiola eh! (CL - 8:54) Bastards!
}

\title{
Sketch 77
}

Mourinho (RM coach): No! (CL - 12:00) A scandal, it's the fact that Guardiola always won with the help of the referees. He was a great coach, but won a Champions League that I would be embarrassed to have (CL - 12:12).

\section{Sketch 78 \\ Journalist: You have been a hero for a generation, parents named their children Pep after you. \\ Guardiola (FCB coach): And if it was a ziga - zaga girl (CL - 13:21) \\ Journalist: And today he is in prison.}

In these conversations, it is clear that the "us" are those from FCB and the "others" are those from Real Madrid. It is a fact that is expressed in the series; in sketch 80, one of the characters mentions:

Kameni (Espanyol player): Ok, ok, let's watch Crackòvia, it's a great programme. (He tries to turn on the television but the remote control does not work, so he is unable to do so - CL - 20:13).

Pochettino (Espanyol coach): Hey! They're doing a comedy sketch about Espanyol on Crackòvia. Odd that it's not about Madrid or Barza (CL - 20:25).

The negative valuations of Spanish contexts, about "the other", are focused on Mourinho (RQ1, RSQ3, RSQ4 and RSQ5), and all the implied valuations in which he is the protagonist are negative. Most of the these appear in a song, which is repeated in sketches 1 and 72, in which it is expressed that "there's nothing else he can do", "go whingeing go", "we all know what you're like" and "what's in store for you Mourinho?".

\section{Sketch 74}

Mourinho (RM coach): Why? Why? (CL - 6:47)

Pizza deliver: Why did Cristiano Ronaldo (RM player) criticise him?

Mourinho (RM coach): No! (CL - 6:53) Why was it that whenever I played against Guardiola (FCB coach) I ended up with just 10 [players].

\section{Sketch 75}

Cristiano (RM player): And why don't we train in the field? Instead of training for the press conference (CL- 9:03).

Di María (RM player): Yes, Cristiano is right (CL - 9:06).

Mourinho (RM coach): Training in the field? What nonsense! (CL - 9:10) 
Di María: You have such weird ideas! (CL - 9:12)

Besides expressing and naming "the others", these humorous conversations propose positive and negative meanings (RSQ4), the nature of which is understood in the symbolic spaces within which they are produced. I should recall that the series is produced and broadcast in a Catalan context, and that Real Madrid is ultimately the quintessential rival of FCB.

\subsubsection{The use of canned laughter in local semantics}

Canned laughter most resoundingly accompanies the implied valuations, of which 83 per cent referred to the Spanish context and 76 per cent to the Catalan context. It is relevant to mention that a very low percentage of valuations about global contexts and characters (explicit 12 per cent and implied 28 per cent) are accompanied by canned laughter.

The qualitative analysis strengthens the idea that humorous messages containing implied valuations need some reinforcement -canned laughter in this case- to direct their coding. However, some studies suggest that the audience "laughed and smiled more, laughed longer, and rated humorous material more favourably when they heard in-group laughter or no laughter at all" (Platow et al. 2005: 542).

The use of canned laughter as a humorous sound resource is present in almost half of the explicit ratings, both those alluding to the Catalan setting (47\%) and to the Spanish setting $(48 \%)$.

The qualitative results of the conversation analysis bring elements to the discussion about humorous discourses as producers of preferred meanings and as imaginaries that propose ideas of a "positive us" and a "negative them". In the case with which this analysis is concerned, the identified referents can be related to the ideological context within which the humorous product was produced. Finally, Figure 2 shows how the qualitative results are related to the Catalan nationalist ideological context (cf. Figure 2).

Figure 2. Qualitative results

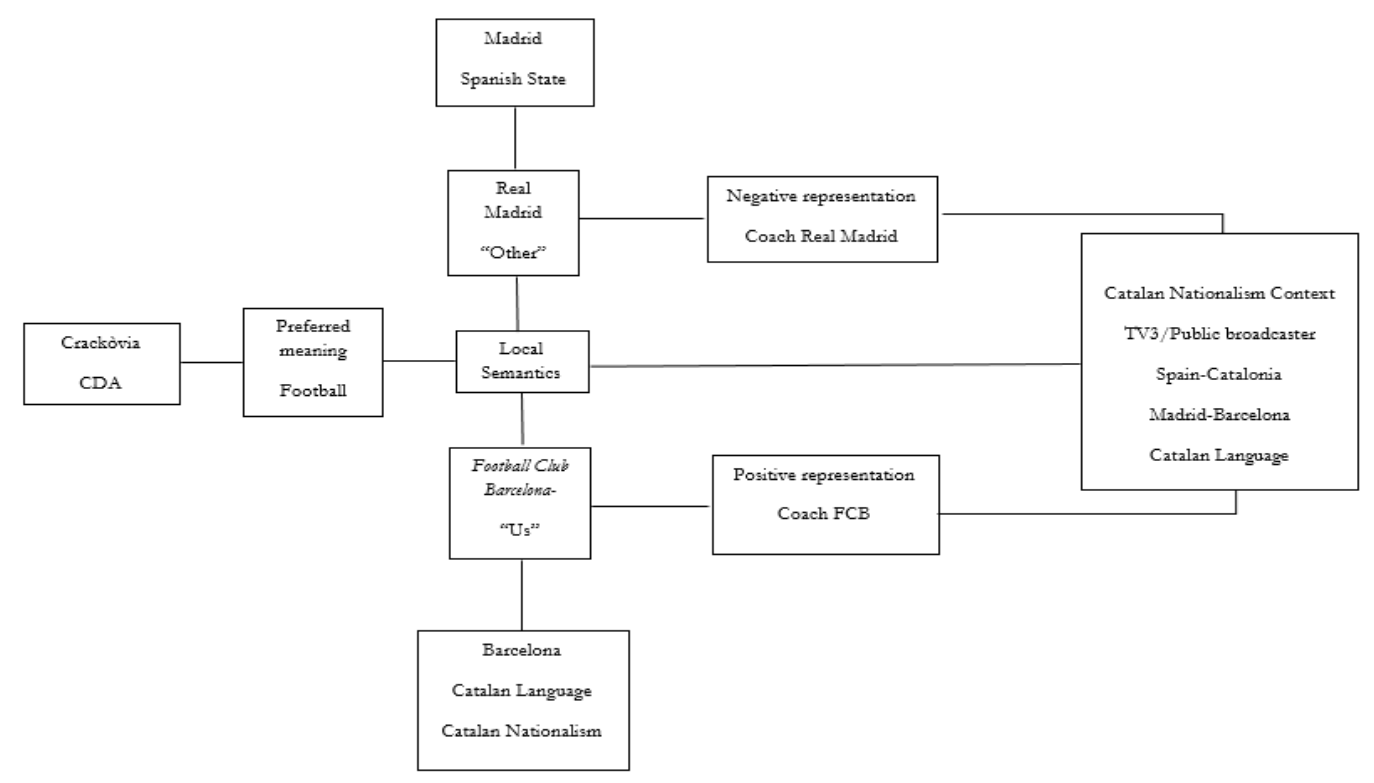

Source: The author 


\section{Discussion and conclusions}

My analysis suggests that a humorous audiovisual text contains preferred and also dominant meanings and that such representations are expressed by how the characters rate other characters, situations, contexts, etc. The nature of the valuations proposes meanings that express local semantics of the positive "us" and the negative "them". The results obtained from the study help to understand how the use of language in humorous narrative contributes to the construction of the image of the "other". It is striking to find that most of the implied representations of the negative "other" are made about Spanish referents and are expressed in Catalan.

In this investigation, the use of the language in the expression of valuations is fundamental to understand how humour behaves in sketches. The fact that the implicit valuations are dependent on the Catalan language is a contribution, a starting point for studies about ethnic humour made in a Catalan context. This result reinforces the idea of the importance of Catalan as one of the actors involved in the process of cultural identity.

Moreover, the cohesion present in the humorous narrative is expressed towards referents close to the context in which the audiovisual text is elaborated, i.e. the Catalan context, and the meanings that express rejection are addressed to Spanish referents. As a local product, the comedy programme does not fight against North American hegemonic imaginaries and referents. The analysis identifies that representations linked to close contexts are the raw material of humorous narrative. In a context of globalised media, the strength of the near, the day-to-day, is where the identity dialogue remains.

To accompany implied valuations and, therefore, direct the audience's emotions, the use of canned laughter is fundamental; it is for explicit valuations too. In the explicit valuations, there is a kind of redundancy in the message because, in principle, the humorous audiovisual text is clear. Even so, canned laughter is added as if it were a signal indicating the start of a humorous event.

While humour techniques such as clownish behaviour, peculiar faces and exaggeration accompany all the valuations made by the series' characters, they use explicit valuations to a lesser extent, possibly because they do not need to do so to express the message clearly. However, the implied valuations need humour techniques to facilitate and direct the presentation of the narration. The humour employs not only traditional literary techniques to generate laughs, jokes, plays on words, etc., but also resources that are particular to televisual and radiophonic language, such as peculiar music, peculiar sound, visual surprise and transformation.

The nature of the valuations is connected with debates and dialogues that go beyond the sphere of fiction. And, from such valuations, it is possible to make out other types of cultural and national tensions that strengthen the rivalry between FC Barcelona as a symbol of proCatalan sentiment and Real Madrid as a symbol of pro-Spanish sentiment (González 2003). Both teams provide a wealth of referents and, as mentioned earlier, football and sports themes use the humour to construct representations of difference. In this situation, the humour of Crackovia exploits not only football but also uses and exposes the rivalry that goes beyond a sporting event, as bank of representatives. It is important to state that the meaning of these valuations should be understood in the context within which they were generated. In any case, this research contributes to the study of audiovisual texts the idea of humour as a cultural 
manager, as an agent that dynamises meanings and symbolic frontiers that go beyond the narrative characteristics of entertainment.

My qualitative analysis concludes that the meanings of the humorous audiovisual text are generated in contexts particular to those within which the series' is produced and broadcast, in settings that are in closer proximity. In some senses, the meanings are engaged in a symbolic struggle and, therefore, create boundaries. But, as Wolfe (1992) says, boundaries are there to be crossed.

One of the limitations of this study is that it is focused on the analysis of the product, the content, the message, and it is missing the narration of the audience. However, it is a phase planned to be executed later and that will complete the analysis, problematise it and contribute more data to the debate of humour as a cultural agent.

Finally, for Catalonia's evolution from its current status as a stateless nation, it is important to study identity issues however they may be expressed, where representations of its culture industries, e.g. television, operate on the subjects' emotional character. As Guibernau (1997) explains, that is not only one of the strengths of such nations, but also the precise sphere within which humour is expressed.

\section{Notes}

[1] El Periódico: http://www.elperiodico.com/es/noticias/tele/20100826/nuevo-Crackòviapara-madrid-castilla-la-mancha-aragon/452690.shtml (accessed 25 May 2012).

[2] http://www.tv3.cat/actualitat/128206/Crackòvia-supera-el-seu-record-daudiencia-i-arribaal-347-de-quota. Corporació Catalana de Mitjans Audiovisuals: http://www.ccma.cat/inici/inici_cas.htm (accessed 1 June 2012).

[3] I have only listed the humour techniques that represent around the 50 per cent mark or more.

\section{References}

Agresti, A. (1996). An Introduction to Categorical Data Analysis. New York: Wiley \& Sons. Archakis, A. \& Tsakona V. (2005). 'Analyzing conversational data in GTVH terms: A new approach to the issue of identity construction via humor'. Humor: International Journal of Humor Research 18 (1), pp. 41-68.

Ball, P. (2011). Morbo: The Story of Spanish Football. London: WSC Books.

Berger, A. (1976). 'Laughing matter: A symposium: Anatomy of the joke'. Journal of Communication 26 (3), pp.113-115.

Berger, A. (1998). An Anatomy of Humor. New Brunswick, Canada: Transaction Publishers.

Bourdieu, P. (2002). Razones prácticas: Sobre la teoría de la acción. Translated by Kauf, Th. Barcelona: Anagrama.

Buijzen, M. \& Valkenburg, P. (2004). 'Developing a typology of humor in audiovisual media'. Media Psychology 6, pp.147-167.

Burke, P., Gurevich, A. \& Le Goff, J. (1999). Una historia cultural del humor. Barcelona: Sequitur.

Camargo, M. (1980). 'The ideological dimension of media messages', in Hall, S., Hobson, D., Lowe, A. \& Willis, P. (eds), Culture, Media, Language, London: Hutchinson, pp. 122-127.

Canclini, N. (2007). 'Entrevista realizada por Alicia Lindón'. Revista Eure 33 (99), pp. 89-99. 
Casetti, F. \& Di Chio, F. (1999). Análisis de la television: Instrumentos métodos y prácticas de investigación. Barcelona: Paidós.

Certeau, M. (1999). La cultura en plural. Buenos Aires: Nueva Visión.

Chapman, A. \& Foot, H. (2007). 'The social responsiveness of young children', in Chapman, A. \& Foot, H. (eds.), Humorous Situations in Humor and Laughter: Theory, Research and Application, New Brunswick, NJ: Transaction Publishers, pp.187-214.

Collantes, F. X., Saperas Lapiedra, E. \& Pujadas Capdevila, E. (1999). La Imatge de Catalunya a les televisions d'àmbit estatal. Barcelona: Consell del Audiovisual de Catalunya.

Cooper, E. (2007). “'Is it something he said?": The mass consumption of Richard Pryor's culturally intimate humour'. The Communication Review 10 (3), pp. 223-247.

Crane, D. (1992). 'High culture versus popular culture revisited: A reconceptualization of recorded cultures', in Lamont, M. \& Fournier, M (eds.), Cultivating Differences: Symbolic Boundaries and the Making of Inequality, Chicago: The University of Chicago Press, pp. 58-74.

Davies, C. (1990). Ethnic Humor around the World: A Comparative Analysis. Bloomington, IN: Indiana University Press.

Dijk, T. (2003). Ideología y Discurso: Una Introducción Multidisciplinaria. Barcelona: Ariel.

Davies, C. (1982). 'Ethnic jokes, moral values, and social boundaries'. British Journal of Sociology 33 (3), pp. 383-403.

Driessen, H. (1999). "The "new immigration" and the transformation of the European-African frontier', in Hastings, D. \& Wilson, T. M. (eds.), New Borders: Frontiers of Identity, Nation and State, Oxford: Berg. pp. 96-116.

Evan, C. (2006). 'Gendered sense of humour as expressed through aesthetic typifications'. Journal of Pragmatics 38 (1), pp. 96-113.

Fairclough, N. (1995). Critical Discourse Analysis. London: Longman.

Fecé, J. (2003). 'Teleseries de producción propia e identidad nacional', in Sampedro, V. (ed), La pantalla de las identidades: Medios de comunicación, políticas y mercados de identidad, Barcelona: Icaria Editorial, pp.285-304.

González, M. (2003). 'La cancha de las identidades: Periodismo deportivo y fútbol "gallego"", in Sampedro, V. (ed), La pantalla de las identidades: Medios de comunicación, políticas y mercados de identidad, Barcelona: Icaria editorial, pp. 259-284.

Fiske, J. (1986). 'Television: Polysemy and popularity'. Critical Studies in Mass Communication 3 (4), pp. 391-408.

Furnham, A. \& Farragher E. (2000). 'A cross-cultural content analysis of sex-role stereotyping in television advertisements: A comparison between Great Britain and New Zealand'. Journal of Broadcasting and Electronic Media 44 (3), pp. 415-436.

Gamson, A. W., Croteau, D., Hoynes, W. \& Sasson, T. (1992). 'Media images and the social construction of reality'. Annual Review of Sociology 18, pp. 373-393.

Guibernau, M. (1997). 'Nations without states: Catalonia, a case study', in Guibernau, M. \& Rex, J. (eds.), The Ethnicity Reader: Nationalism, Multiculturalism and Migration, Cambridge: Polity Press, pp. 133-153.

Gifreu, J. (2001). El meu País: Narratives i Combats per la Identitat. Lleida, Spain: Pagès Editors.

Hall, S. (1977). Representation: Cultural Representations and Signifying Practices. London: Sage.

Hall, S. (1980). 'Encoding/decoding', in Hall, S., Hobson, D., Lowe, A. \& Willis, P. (eds), Culture, Media, Language. London: Hutchinson, pp. 128-138. 
Hartley, J. (2000). Los usos de la televisión. Barcelona: Paidós Comunicación.

Jontes, D. (2010). 'Slovenian sitcom and the construction of otherness'. Cultural Studies 24 (5), pp. 716-728.

Kotthoff, H. (2006). 'Gender and humour: The state of the art'. Journal of Pragmatics 38 (1), pp. 4-25.

Krieger, R. (2003). "Does he actually say the word Jewish?": Jewish representations in Seinfeld'. Journal for Cultural Research 7 (4), pp. 387-404.

Kuipers, G. (2006). Good Humor, Bad Taste: A Sociology of the Joke. Berlin: Mouton de Gruyter.

Kuipers, G. (2009). 'Humour styles and symbolic boundaries'. Journal of Literary Theory 3 (2), pp. 219-239.

Landis, R. \& Koch G. (1977). 'The measurement of observer agreement for categorical data'. Biometrics 33, pp. 159-174.

Lavado, A. (2010). 'El consumo de YouTube en España'. Global Media Journal 14 (7), pp. 76-92.

Lull, J. (1997). 'HELP! Cultura e identidad en el siglo XXI'. Diálogos de la Comunicación 48 , pp. 57-68.

Martínez, L. (2009). 'La contribución del humour, de la comedia de situación a la identidad cultural catalana'. Comunicación y Sociedad 12 (1), pp. 223-241.

Morley, D. (1996). Televisión, Audiencias y Estudios Culturales. Buenos Aires: Amorrortu.

McIntosh, W. D., Murray, J. D., Murray, R. M. \& Manian, S. (2006). 'Sexual humor in Hollywood films: Influences of social and economic threat on the desirability of male and female characters'. Mass Communication and Society 9 (2), pp. 239-254.

McLure, L. (2005). 'Women and humor in Classical Greece'. American Journal of Philology 125 (4), pp. 615-618.

Meyer, J. (2000). 'Humour as a double-edged sword: Four functions of humour in communication'. Communication Theory 10 (3), pp. 310-331.

Moragas, M. (1988). Espais de comunicació: Experiències i perspectives a Catalunya. Barcelona: Edicions 62.

Paolucci, P. \& Richardson M. (2006). 'Sociology of humour and a critical dramaturgy'. Symbolic Interaction 29 (3), pp. 331-348.

Paton, G. (1988). 'In search of literature on the sociology of humour: A sociobibliographical afterword', in Powell, C. \& Paton, G. (eds.), Humour in Society: Resistance and Control, London: Macmillan, pp. 260-271.

Platow, M. J., Haslamb, A. S., Both, A., Chew, I., Cuddon, M., Goharpey, N., Maurer, J., Rosini, S., Tsekouras, A. \& Diana, D. M. (2005). “'It's not funny if they're laughing": Self-categorization, social influence, and responses to canned laughter'. Journal of Experimental Social Psychology 41, pp. 542-550.

Price, M. (1995). Television, the Public Sphere, and National Identity. Oxford: Clarendon Press.

Raskin, V. (1985). Semantic Mechanisms of Humor. Dordrecht: D. Reidel.

Robinson, D. \& Lynn S. (2001). 'Getting a laugh: Gender, status, and humor in task discussions'. Social Forces 80 (1), pp.123-158.

Rod, M. (2007). The Psychology of Humor: An Integrative Approach. Burlington, MA: Elsevier Academic Press.

Romero, E., Alsua, C. J., Hinrichs, K. T. \& Pearson, T. R. (2007). 'Regional humor differences in the United States: Implications for management'. Humor: International Journal of Humor Research 20 (2), pp. 189-201. 
Rutherford, J. (1990). Identity, Community, Culture, Difference. London: Lawrence \& Wishart.

Sampedro, V. (2003). 'Medios de comunicación, políticas y mercados de identidad', in Sampedro, V. (ed.), La pantalla de las identidades: Medios de comunicación, políticas y mercados de identidad, Barcelona: Icaria Editorial, p. 9-28.

Scharrer, E., Bergstrom, A., Paradise, A. \& Ren, Q. (2006). 'Laughing to keep from crying: Humor and aggression in television commercial content'. Journal of Broadcasting and Electronic Media 50 (4), pp. 615-634.

Schifman, L. \& Thelwall, M. (2009). 'Assessing global diffusion with Web memetics: The spread and evolution of a popular joke'. Journal of Cultural Studies 5 (4), pp. 450-470.

Villena, S. (2002). 'El fútbol y las identidades: Balance preliminar sobre el estado de la investigación en América Latina'. Iconos: Revista de Ciencias Sociales (14), pp. 126-136.

Waisbord, S. (2004). 'McTV: Understanding the global popularity of television formats'. Television \& New Media 5 (4), pp. 359-383.

Willians, R. (2003). Palabras Clave: Un vocabulario de la cultura y la Sociedad. Buenos Aires: Nueva Visión.

Wolfe, A. (1992). 'Democracy versus sociology: Boundaries and their political consequences', in Lamont, M. \& Fournier, M. (eds), Cultivating Differences: Symbolic Boundaries and the Making of Inequality, Chicago: The University of Chicago Press, pp. 309-326.

Wolton, D. (1995). Elogio del gran public: Una teoría crítica de la televisión. Barcelona: Gedisa. 